\title{
ZEB1 is Negatively Correlated with E-Cadherin in Prostatic Anomaly Tissue
}

\author{
Sari Eka Pratiwi ${ }^{1}$, Sri Nuryani Wahyuningrum ${ }^{2}$, Rachmagreta Perdana Putri ${ }^{3}$, Danarto ${ }^{4}$, \\ Didik Setyo Heriyanto ${ }^{5}$, Nur Arfian ${ }^{6}$, Sofia Mubarika Haryana7 ${ }^{7}$ Indwiani Astuti8 \\ ${ }^{1}$ Department of Biology and Pathobiology, Faculty of Medicine, Universitas Tanjungpura, Pontianak, Indonesia \\ ${ }^{2}$ Magelang Unit of Health Research and Development, Ministry of Health, Magelang, Indonesia \\ ${ }^{3}$ Department of Histology, Faculty of Medicine, Universitas Ahmad Dahlan, Yogyakarta, Indonesia \\ ${ }^{4}$ Department of Urology, Sardjito Hospital, Yogyakarta, Indonesia \\ ${ }^{5}$ Department of Anatomy Pathology, Faculty of Medicine, Public Health and Nursing, Universitas Gadjah Mada, Yogyakarta, \\ Indonesia \\ ${ }^{6}$ Department of Anatomy, Faculty of Medicine, Public Health and Nursing, Universitas Gadjah Mada, Yogyakarta, Indonesia \\ ${ }^{7}$ Department of Histology and Cell Biology, Faculty of Medicine, Public Health and Nursing, Universitas Gadjah Mada, \\ Yogyakarta, Indonesia \\ ${ }^{8}$ Department of Pharmacology, Faculty of Medicine, Public Health and Nursing, Universitas Gadjah Mada, Yogyakarta, Indonesia
}

Background: Prostatic anomalies are common in tumor or infection condition. The enlargement of prostate gland affects the epithelial cell polarity that involves epithelial-mesenchymal transition (EMT). Transition into mesenchymal is mediated by transcription factor ZEB1 and E-cadherin protein. Upregulation of ZEB1 and loss of E-Cadherin expression were associated to proliferation and metastasis of malignancy cells. This study aims to describe the correlation of ZEB1 and E-cadherin expression in prostatic anomaly.

Materials and method: Samples were Formalin Fixed Paraffin Embedded (FFPE) block consist of 8 block Benign Prostatic Hyperplasia (BPH), 6 blocks High Grade Prostatic Intraepithelial Neoplasia (HGPIN) and 6 blocks Prostate Carcinoma (PCA). The blocks then sliced into 5 sections to be prepared for RNA extraction procedures. ZEB1 and E-Cadherin expression was analyzed by semi-quantitative procedures using PCR and electrophoresis. Correlation between ZEB1 and E-Cadherin espression was analyzed using Spearman's rank correlation.

Results: Relative expression of ZEB1 and E-cadherin mRNA in each group of prostatic anomaly were not significantly different $(p>0.05)$. ZEB1 and E-Cadherin mRNA expression showed a significant and moderate level of negative correlation $(p<0.05$; $0.40<r<0.59)$. Increasing of ZEB1 mRNA expression will be followed by decreasing of E-Cadherin mRNA expression.

Conclusion: ZEB1 negatively correlates with E-cadherin due to EMT process in prostatic anomaly. High expression of ZEB1 induced down-regulation of E-cadherin and vise versa. Various studies can be developed, especially the development of targeted therapy against ZEB1 to suppress the EMT process by increasing the expression of E-cadherin.

Keywords: epithelial-mesenchymal transition (EMT), ZEB1, E-Cadherin, BPH, HGPIN, PCA

Date of submission: September 9, 2021

Last Revised: October 16, 2021

Accepted for publication: October 18, 2021

Corresponding Author:

Sari Eka Pratiwi

Department of Biology and Pathobiology

Faculty of Medicine, Universitas Tanjungpura

J. Profesor Dokter Haji Hadari Nawawi, Pontianak 78115, Indonesia

e-mail: sariekapratiwi@medical.untan.ac.id

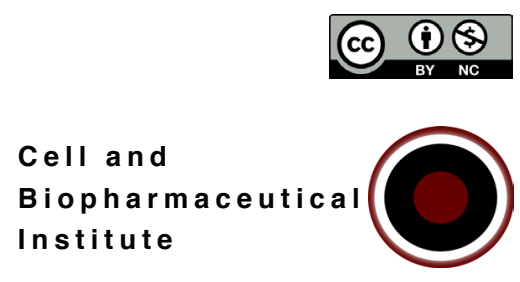




\section{Introduction}

The prostate gland is part of male reproductive system that produce semen fluid and carry sperm from testicles when penis has ejaculating. ${ }^{1}$ The size of prostate width, height and length tend to increase with age. ${ }^{2}$ Several common prostatic anomaly are Benign Prostatic Hyperplasia (BPH), Prostatic Intraepithelial Neoplasia (PIN) and Prostate Adenocarcinoma (PCA). One of the most common urologic diseases is BPH, which is often found in elderly people. ${ }^{3}$ The other prostatic gland anomaly is PIN, categorized as low grade PIN (PIN1), and high grade PIN (PIN1 or PIN2). ${ }^{3,4}$ The anomaly that leads to PCA is High Grade Prostatic Intraepithelial Neoplasia (HGPIN). The incidence of HGPIN increases with the age of the patient. Patients with HGPIN have 15 times more risk for adenocarcinoma prostate development compared to those without HGPIN. ${ }^{4}$ Meanwhile, it is difficult to differentiate HGPIN and PCA. Some recent studies still encounter difficulties to distinguish HGPIN from BPH because of the similarity of their morphology. ${ }^{5}$

PCA is the second highest occurring cancer and leading cause of death among men in America and Europe. ${ }^{6}$ In Asia, the prevalence of prostate adenocarcinoma is 7.2 of 100,000 men each year. In Indonesia, the incidence of PCA for the last 8 years was 1,102 patients, with mean age of 67 years old and 50\% found in advanced stages. ${ }^{7}$ While localized prostate cancer is often slow-growing and clinically stable, meta-static spread lowers the possibility of survival and therapy is rarely curative. The mortality rate is associated with metastasis. ${ }^{8-10}$

It has been reported that tumor progression and metastasis associate with epithelial-mesenchymal transition (EMT). This transition altered interaction of cell-cell, cellextracellular matrix and induce epithelial cell forming mesenchymal phenotype with higher motility. ${ }^{11}$ Indeed, EMT occurs in normal development. It is reversible and, in some cases, cells undergo mesenchymal to epithelial transition (MET). In normal development, EMT and MET were highly planned and regulated, whereas in tumorigenesis, the order of mechanism is uncertain, time-independent, or some pathway maybe miss-regulated. During tumorigenesis, molecular program leads to EMT as consequence of oncogenic signaling. ${ }^{12}$ EMT is found well correlated with poor prognosis of neoplastic disease. Activation of EMT has been marked as critical process for anomaly and malignant phenotypes of cells. The role of EMT support malignant cell to invades, migrates and metastasis in distant organs. ${ }^{13}$ EMT dysregulation is reported found in various malignant cell, like breast, prostate, colon and lung. . $^{14-17}$

Transition into mesenchymal or epithelial cell surface polarity is mediated by E-cadherin protein. ${ }^{12}$ In association with EMT during tumorigenesis, the expression of E-cadherin is down-regulate, resulting loss of cell-cell adhesion and cell junction and promote malignant cell to invade surrounding tissue and migrate to distant organ. ${ }^{18}$ Loss of E-cadherin expression has been reported in many human malignancies. ${ }^{19-22}$

There are several transcription factors, which are involved in the EMT process, and one of them is zinc finger Enhancer Box (E-Box) binding homeobox 1 (ZEB1). ZEB1 promotes EMT through suppressing the cell adhesion protein E-cadherin, which is prominent glycoprotein in controlling the epithelial phenotype. ${ }^{23}$ ZEB-1 suppress E-cadherin expression through binding to E-box in the promoter of Cadherin 1 (CDH1) and recruits $\mathrm{C}$-terminal binding protein $(\mathrm{CtBP})$ transcriptional co-repressors, triggering to suppressed CDH1 transcription and promote EMT. ${ }^{24}$ It has been reported that up-regulation of ZEB-1 expression plays a role in progression and metastasis in various tumor. ${ }^{25-27}$ Among EMT markers, the clinical importance of ZEB1 in PCA has been shown. Indeed, its expression is boosted according to the various progression steps of PCA and is correlated with reduced overall survival. ZEB1 is a key transcription factor for EMT that promotes multi-drugs resistance, proliferation, and metastasis..$^{28,29}$

Association of E-cadherin and ZEB1 as regulator in EMT process has been showed in many studies. In Indonesia, study about this association is still rarely done, especially in prostatic anomaly condition. In this study, we describe a correlation of E-cadherin and ZEB1 expression in prostatic anomaly using Formalin Fixed Paraffin Embedded (FFPE) samples.

\section{Materials and methods}

\section{Sample Collection}

This was a cross-sectional study which involved 20 patients with prostatic anomaly. Samples were FFP block from Laboratory of Cito Yogyakarta which stored from 2017 until 2018, in collaboration with Anatomical-Pathology Department of Medical Faculty, Universitas Gadjah Mada. Samples were taken purposively regarding prostatic anomaly tissue were difficult to obtained. Detail of subjects 
identity were confidential and not showed in this study. Samples consist of 8 block of BPH, 6 blocks of HGPIN and 6 blocks of PCA. The blocks then sliced into 5 sections to be prepared for RNA extraction procedures. This study was approved by Medical and Health Ethics Comittee of Medical Faculty, Universitas Gadjah Mada (Ref: KE/ FK/0888/EC/2018).

\section{Total RNA Extraction and Reverse Transcriptase-PCR (RT-PCR)}

Total RNA was extracted from FFPE sections using miRNeasy FFPE Kit (Cat. No. 217504, Qiagen, Hilden Germany). After FFPE blocks were sliced, the sections were placed in safe lock tubes $(1.5 \mathrm{~mL})$, and $160 \mu \mathrm{L}$ Xylene was added to each tube, for deparaffinization process. The RNAs were eluted in $30 \mu \mathrm{L}$ RNase-free water. RNA concentration and purity was calculated using Nanodrop (NanoVue Plus, GE Healthcare, Life Science, Chicago, IL, USA). The cDNA synthesis was carried out by reverse transcription reactions using miRCURY LNA RT Kit (Cat. No 339340, Qiagen) and ReverTra Ace ${ }^{\circledR}$ qPCR RT Master Mix with gDNA remover (FSQ-301, Toboyo, New York, NY, USA). All the process were performed using thermal cycler (Cat. No. A248111, Applied Biosystems, Waltham, MA, USA) following the manufacturer's guidelines. The cDNA were stored at $-20^{\circ} \mathrm{C}$ until further analysis.

\section{PCR and Electrophoresis of E-Cadherin and ZEB1 mRNA}

E-Cadherin (CDH1) and ZEB1 mRNA expression was analyzed by semi-quantitative procedures using PCR and electrophoresis, compared to $\beta$-actin expression as housekeeping gene. This study used GoTaq ${ }^{\circledR}$ Green Master Mix (Promega, Madison, WI, USA). Master Mix as much as $12.5 \mu \mathrm{L}$, forward primer $1 \mu \mathrm{L}$, reverse primer $1 \mu \mathrm{L}$ and nuclease free water $9.5 \mu \mathrm{L}$ were added into $3 \mu \mathrm{L}$ cDNA template. Annealing temperature for ZEB1 and E-Cadherin were set at $57^{\circ} \mathrm{C}$ and for $\beta$-actin at $56^{\circ} \mathrm{C}$, for 40 cycles. Then, followed by electrophoresis procedure in agarose gel $2 \%$, at $100 \mathrm{~V}$ for 12 minutes. We used ImageJ software to analyze the intensity of electropherogram bands' densities. The mRNA primer sequences are showed in Table 1.

\section{Data Analysis}

Data were analyzed using SPSS 21 (IBM Corporation, Armonk, NY, USA). Subject characteristics were described as mean and standard deviation (minimal and maximal score), or as total number (n) and percentage. Mean difference were analyzed using non-parametric KruskalWallis test. Correlation between ZEB1 and E-Cadherin mRNA expression was analyzed using Spearman's rank correlation. Statistically significant is considered when $p$-value $<0.05$.

\section{Results}

\section{Subject Characteristic}

This study involved 20 subjects of prostatic anomaly, who consist of 8 patients of BPH, 6 patients of HGPIN and 6 patients of PCA. Patient were dominated by elderly with average of age was 68 years old. Relative expression of E-cadherin and ZEB1 in each group of prostatic anomaly were not significantly different $(p>0.05)$. Subject's characteristic was shown in Table 2.

\section{Correlation of ZEB-1 and E-Cadherin mRNA Relative Expression}

Based on bivariate correlation analysis, ZEB1 and E-Cadherin mRNA expression showed a significant and moderate level of negative correlation $(p<0.05 ; 0.40<\mathrm{r}$ $<0.59)$. This was means that increasing of ZEB1 mRNA expression will be followed by decreasing of E-Cadherin mRNA expression, and vice versa. ZEB1 mRNA expression

Table 1. Primer sequence of ZEB1, E-Cadherin and $\beta$-actin.

\begin{tabular}{lllc}
\hline & mRNA & \multicolumn{1}{c}{ Primer Sequences } & Product Lenght \\
\hline ZEB1 & Forward & 5'-CGGCGCAATAACGCTGTTT -3' & \multirow{2}{*}{ 166 bp } \\
& Reverse & 5'- GTTCTCACACCCCACACCTC-3' & \\
\hline CDH1 & Forward & 5'- TCATGAGTGTCCCCCGGTAT -3' & \multirow{2}{*}{$240 \mathrm{bp}$} \\
& Reverse & 5'-TCTTGAAGCGATTGCCCCAT -3' & \\
\hline \multirow{2}{*}{-actin } & Forward & 5'-CGCGAGAAGATGACCCAGATC-3' & \multirow{2}{*}{$125 \mathrm{bp}$} \\
& Reverse & 5'-TCACCGGAGTCCATCACGA-3' & \\
\hline
\end{tabular}


Table 2. Subject characteristic with prostatic anomaly.

\begin{tabular}{lcc}
\multicolumn{1}{c}{ Characteristic of Subject } & Value (n=20) & $p$-value \\
\hline Age (years), mean \pm SD (min-max) & $68 \pm 11.4(44-81)$ & - \\
\hline Prostatic Anomaly Status, n (\%) & & - \\
BPH & $8(40)$ & \\
HGPIN & $6(30)$ & \\
PCA & $6(30)$ & $0.781^{\mathrm{a}}$ \\
\hline Average of ZEB1 Relative expression, & & \\
mean \pm SD (min-max) & $1.98 \pm 0.38(1.56-2.67)$ & \\
BPH & $2.06 \pm 0.35(1.57-2.58)$ & \\
HGPIN & $2.05 \pm 0.25(1.81-2.51)$ & \\
PCA & & \\
\hline Average of E-Cadherin relative & & \\
expression, mean \pm SD (min-max) & & \\
BPH & $0.62 \pm 0.32(0.13-0.99)$ & \\
HGPIN & $0.61 \pm 0.28(0.18-0.90)$ & \\
PCA & $0.72 \pm 0.31(0.24-1.12)$ & \\
\hline
\end{tabular}

andependent-samples Kruskal-Wallis test; significant if $p$-value $<0.05$.

could affect E-Cadherin mRNA expression as much as $30,8 \%\left(\mathrm{R}^{2}=0.308\right)$. Correlation of ZEB1 and E-Cadherin were shown in Figure 1. Meanwhile, average of ZEB1 and E-Cadherin mRNA expression were shown in Figure 2. Average of ZEB1 mRNA expression was $2.03 \pm 0.32$ fold, and average of E-Cadherin mRNA expression was $0.65 \pm 0.29$ fold.

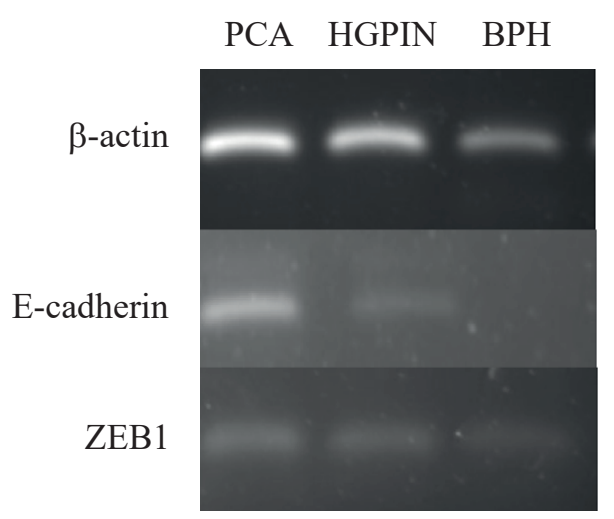

Figure 1. Gel Electrophoresis result of $\beta$-Actin (125bp), E-cadherin (240bp), and ZEB1 (166bp).

\section{Discussion}

Down-regulation of E-cadherin expression has been studied in many prostatic anomalies. ${ }^{30,31}$ In line with current study, E-cadherin expression in BPH, HGPIN and PCA were in suppressed condition. A study using immunostaining on BPH specimen showed a reduced point of tight junction, destabilization of tight junction formation, increased of epithelial permeability, leakage of prostate-specific antigen and other secretory protein from glandular lumen into stromal compartment, as consequence of E-cadherin downregulation. ${ }^{30}$ In prostatic intraepithelial neoplasia, lost of E-cadherin expression promote cell apoptosis and interfere epithelial integrity. ${ }^{31}$ E-cadherin downregulation is a hallmark of EMT, and equally followed by mesenchymal neural cadherin (N-cadherin) upregulation. This transition induce cells to lose affinity and facilitate cell migration to distant organ. ${ }^{32}$ Alteration in normal E-cadherin structure and function resulting abnormal tissue architecture and onset of disease. ${ }^{33}$ The role of cell-cell adhesion in the metastasis of cancer has been investigated. To permit extravasation from the primary tumor and subsequent metastasis, the loss of 


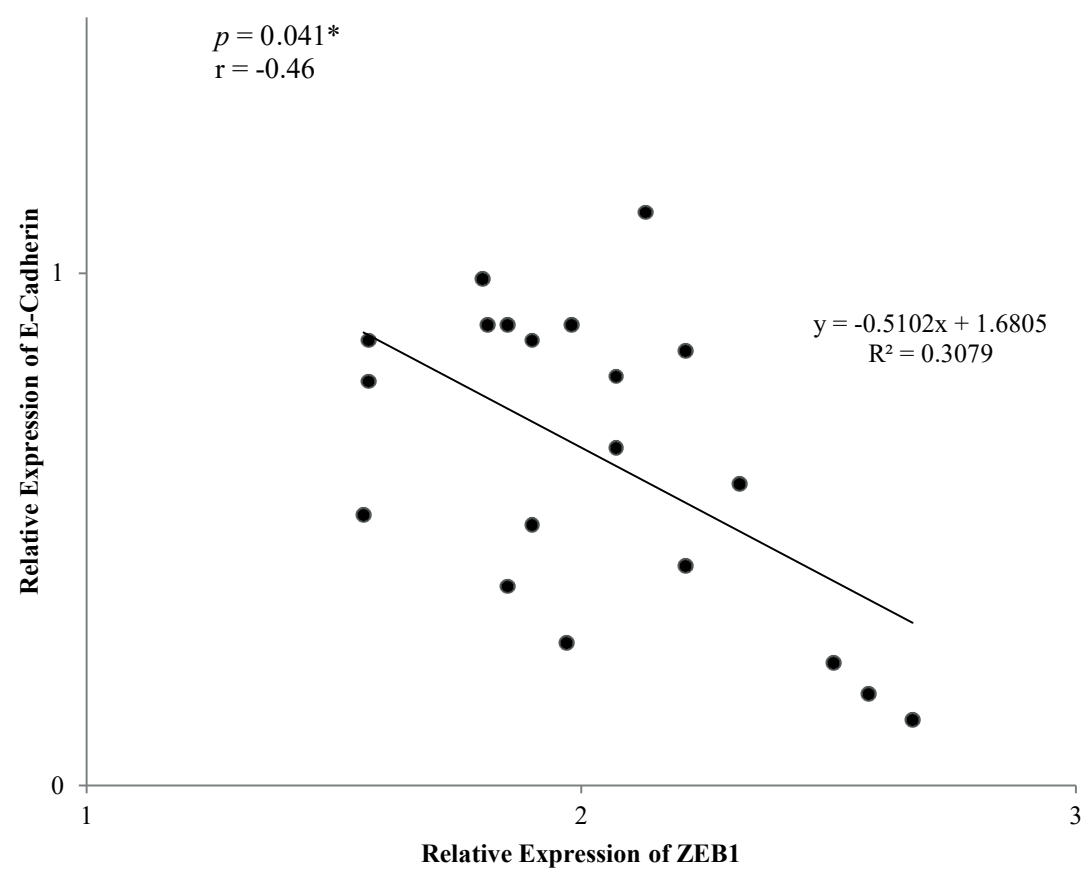

Figure 2. Average of ZEB1 and E-Cadherin relative expression in prostatic anomaly. cell-cell adhesion is essential, and the loss of cell adhesion molecules has been associated with cancer progression. ${ }^{10}$

E-cadherin is a transmembrane protein that plays a key role in migration and cell adhesion. The $\beta$-catenin/APC pathway, which relates to cell proliferation and EMT, also involves E-cadherin. E-cadherin deficiency is associated with poor prognosis for all human patients with high-grade prostate tumors. E-cadherin downregulation in human medicine has been associated with numerous mechanisms, including copy number loss, somatic mutations, methylation, and inhibition mediated by ZEB1 and SRC family kinases. ${ }^{22,34}$

During EMT process, E-cadherin expression in transcriptional level is repressed by nuclear factor (E-cadherin transcriptional repressors, EcTRs) such as ZEB1. ZEB1 binds to E-box sequences of E-cadherin promoter region to suppress E-cadherin transcription. ${ }^{32}$ ZEB1 has high specificity binding to E-box sequences of E-cadherin promoter region due to its helix-loop-helix motif. This motif is commonly found in transcription factors that bind DNA. ${ }^{29}$ ZEB1 as transcription factors can induce this epithelial-to-mesenchymal switch. ${ }^{10}$

This result study was in line with previous study that E-cadherin and ZEB1 expression is negatively correlates. An in vitro study of prostate cancer cells revealed that ZEB1 plays an important role for transendhotelial migration of prostate cancer cell line. Many of epithelial genes, including
E-cadherin, were downregulate in condition of ZEB1 highly expressed. On contrary, in ZEB1 silenced cells, E-cadherin expression is highly expressed. This condition promotes migration and invasion of tumor-stroma interface. ${ }^{27}$ Loss of E-cadherin and up-regulated ZEB1 expression has been associated with poor clinical condition in many malignancies, including prostate cancer. High expression of ZEB1 is associated with high Gleason score in prostate adenocarcinomas, and promotes aggressive phenotype in prostate cancer cell. ${ }^{35,36}$ Recent studies showed that upregulation of ZEB1 induces chemoresistance due to enhanced DNA damage response and DNA repair ability. ${ }^{37}$ Moreover, downregulation of E-cadherin expression from paraffin-embedded tumor tissue sample of patients with localized prostate cancer associated with recurrence of prostate cancer after one-year post-surgical. ${ }^{38}$

Limitation of this study was obtained in small sample size of patient with prostatic anomaly. However, our study provides more insight about correlation of E-cadherin and ZEB1 expression in BPH, HGPIN and PCA paraffinembedded tissue samples, especially in Indonesian patients.

\section{Conclusion}

In conclusion, our research has shown that ZEB1 is negatively correlate with E-cadherin mRNA expression due to EMT process in prostatic anomaly. High expression 
of ZEB1 induced down-regulation of E-cadherin in BPH, HGPIN and PCA patients. This result may suggest an appropriate therapeutic target to prevent severity of illness and minimize the side effect of therapies. Various studies can be developed, especially the development of targeted therapy against ZEB1 to suppress the EMT process by increasing the expression of E-cadherin.

\section{Acknowledgments}

Appreciations are given to staff of the anatomy laboratory, pathological anatomy laboratory, molecular biology laboratory, biochemistry laboratory, along with all of academician of the Faculty of Medicine, Public Health and Nursing, Universitas Gadjah Mada.

\section{References}

1. Lee $\mathrm{CH}$, Akin-Olugbade O, Kirschenbaum A. Overview of prostate anatomy, histology, and pathology. Endocrinol Metab Clin North Am. 2011; 40(3): 565-75.

2. Zhang SJ, Qian HN, Zhao Y, Sun K, Wang HQ, Liang GQ, et al. Relationship between age and prostate size. Asian J Androl. 2013; 15(1): 116-20.

3. Greco F, Inferrera A, La R, Navarra M, Casciaro M, Grosso G, et al. The potential role of micrornas as biomarkers in benign prostatic hyperplasia: a systematic review and meta-analysis. Eur Urol Focus. 2018; 5(3): 497-507.

4. Al-Dabbagh AA-D, Mohammad EJ, Jaffal WN. Is high grade prostatic intraepithelial neoplasia a risk factor for prostate cancer? - a local study. Open J Urol. 2018; 8(1): 81765. doi: 10.4236/oju.2018.81001.

5. Zynger DL, Yang X. High-grade prostatic intraepithelial neoplasia of the prostate : the precursor lesion of prostate cancer. Int J Clin Exp Pathol. 2009; 2(4): 327-38.

6. American Cancer Society [Internet]. Cancer Facts and Figures 2017 [cited 2022 Jul 30]. Available from: https://www.cancer. org/research/cancer-facts-statistics/all-cancer-facts-figures/cancerfacts-figures-2017.html

7. Komite Penanggulangan Kanker Nasional. Pedoman Nasional Pelayanan Kedokteran Kanker Paru. Jakarta: Kementrian Kesehatan RI; 2017.

8. Wong MCS, Goggins WB, Wang HHX, Fung FDH, Leung C, Wong SYS, et al. Global incidence and mortality for prostate cancer: analysis of temporal patterns and trends in 36 countries. Eur Urol. 2016; 70(5): 862-74.

9. Bashir MN. Epidemiology of prostate cancer. Asian Pac J Cancer Prev. 2015; 16(13): 5137-41.

10. Voss G, Haflidadóttir BS, Järemo H, Persson M, Catela Ivkovic $\mathrm{T}$, Wikström $\mathrm{P}$, et al. Regulation of cell-cell adhesion in prostate cancer cells by microRNA-96 through upregulation of E-Cadherin and EpCAM. Carcinogenesis. 2020; 41(7): 865-74.

11. Pasquier J, Abu-Kaoud N, Al Thani H, Rafii A. Epithelial to mesenchymal transition in a clinical perspective. J Oncol. 2015; 2015: 792182. doi: 10.1155/2015/792182.

12. Larue L, Bellacosa A. Epithelial-mesenchymal transition in development and cancer: Role of phosphatidylinositol 3' kinase/ AKT pathways. Oncogene. 2005; 24(50): 7443-54.

13. Kalluri R, Weinberg RA. Review series The basics of epithelialmesenchymal transition. J Clin Invest. 2009; 119(6): 1420-8.

14. Burton LJ, Hawsawi O, Loyd Q, Henderson V, Howard S, Harlemon $\mathrm{M}$, et al. Association of epithelial mesenchymal transition with prostate and breast health disparities. PLoS One. 2018; 13(9): e0203855. doi: 10.1371/journal.pone.0203855.

15. Tsoukalas N, Aravantinou-Fatorou E, Tolia M, Giaginis C, Galanopoulos M, Kiakou M, et al. Epithelial-mesenchymal transition in non small-cell lung cancer. Anticancer Res. 2017; 37(4): 1773-8.

16. Montanari M, Rossetti S, Cavaliere C, D'Aniello C, Malzone M, Vanacore $\mathrm{D}$, et al. Epithelial-mesenchymal transition in prostate cancer: an overview. Oncotarget. 2017; 8(21): 35376-89.

17. Loboda A, Nebozhyn M V., Watters JW, Buser CA, Shaw PM, Huang $\mathrm{PS}$, et al. EMT is the dominant program in human colon cancer. BMC Med Genomics. 2011; 4: 9. doi: 10.1186/1755-8794-4-9.

18. Petrova YI, Schecterson L, Gumbiner BM. Roles for E-cadherin cell surface regulation in cancer. Mol Biol Cell. 2016; 27(21): 3233-44.

19. Sugihara T. Loss of adherens junction protein e-cadherin is a biomarker of high-grade histology and poor prognosis in endometrial cancer Ann Clin Lab Res. 2016; 4(1): 1-5.

20. Fei Y, Liu XS, Wang F, Wang W, Liu SL. E-cadherin expression in normal and abnormal tissue specimens from patients with pancreatic carcinoma. Lab Med. 2010; 41(8): 473-7.

21. Repetto O, De Paoli P, De Re V, Canzonieri V, Cannizzaro R. Levels of soluble e-cadherin in breast, gastric, and colorectal cancers. Biomed Res Int. 2014; 2014: 408047. doi: 10.1155/2014/408047.

22. Fonseca-Alves CE, Kobayashi PE, Leis-Filho AF, Lainetti P de F, Grieco V, Kuasne $\mathrm{H}$, et al. E-cadherin downregulation is mediated by promoter methylation in canine prostate cancer. 2019; 10: 1242 . doi: 10.3389/fgene.2019.01242.

23. Aigner K, Dampier B, Descovich L, Mikula M, Sultan A, Schreiber $\mathrm{M}$, et al. The transcription factor ZEB1 (deltaEF1) promotes tumour cell dedifferentiation by repressing master regulators of epithelial polarity. Oncogene. 2007; 26(49): 6979-88.

24. Zhang P, Sun Y, Ma L. ZEB1: At the crossroads of epithelialmesenchymal transition, metastasis and therapy resistance. Cell Cycle. 2015; 14(4): 481-7.

25. Ran J, Lin DL, Wu RF, Chen QH, Huang HP, Qiu NX, et al. ZEB1 promotes epithelial-mesenchymal transition in cervical cancer metastasis. Fertil Steril. 2015; 103(6): 1606-1614.e2.

26. Ma Y, Zheng X, Zhou J, Zhang Y, Chen K. ZEB1 promotes the progression and metastasis of cervical squamous cell carcinoma via the promotion of epithelial-mesenchymal transition. Int J Clin Exp Pathol. 2015; 8(9): 11258-67.

27. Drake J, Strohbehn G, Bair T, Moreland J, Henry M. ZEB1 enhances transendothelial migration and represses the epithelial phenotype of prostate cancer cells. Mol Biol Cell. 2009; 20(8): 2207-17.

28. Bery F, Figiel S, Kouba S, Fontaine D, Guéguinou M, Potier-Cartereau $\mathrm{M}$, et al. Hypoxia promotes prostate cancer aggressiveness by upregulating EMT-activator Zeb1 and SK3 channel expression. Int J Mol Sci. 2020; 21(13): 4786. doi: 10.3390/ijms21134786.

29. Wong TS, Gao W, Chan JYW. Transcription regulation of E-cadherin by zinc finger E-box binding homeobox proteins in solid tumors. Biomed Res Int. 2014; 2014: 921564. doi: 10.1155/2014/921564.

30. Li F, Pascal LE, Stolz DB, Wang K, Zhou Y, Chen W, et al. E-cadherin is downregulated in benign prostatic hyperplasia and required for 
tight junction formation and permeability barrier in the prostatic epithelial cell monolayer. Prostate. 2019; 79(11): 1226-37.

31. Olson A, Le V, Aldahl J, Yu EJ, Hooker E, He Y, et al. The comprehensive role of E-cadherin in maintaining prostatic epithelial integrity during oncogenic transformation and tumor progression. PLoS Genet. 2019; 15(10): e1008451. doi: 10.1371/ journal.pgen.1008451.

32. Lamouille S, Xu J, Derynck R. Molecular mechanisms of epithelialmesenchymal transition. Nat Rev Mol Cell Biol. 2014; 15(3): 17896.

33. Guilford P. E-cadherin downregulation in cancer: Fuel on the fire? Mol Med Today. 1999; 5(4): 172-7.

34. Xiong H, Hong J, Du W, Lin YW, Ren LL, Wang YC, et al. Roles of STAT3 and ZEB1 proteins in E-cadherin down-regulation and human colorectal cancer epithelial-mesenchymal transition. J Biol Chem. 2012; 287(8): 5819-32.
35. Graham TR, Zhau HE, Odero-Marah VA, Osunkoya AO, Kimbro $\mathrm{KS}$, Tighiouart M, et al. Insulin-like growth factor-I - Dependent up-regulation of ZEB1 drives epithelial-to-mesenchymal transition in human prostate cancer cells. Cancer Res. 2008; 68(7): 2479-88.

36. Orellana-Serradell O, Herrera D, Castellon E, Contreras H. The transcription factor ZEB1 promotes an aggressive phenotype in prostate cancer cell lines. Asian J Androl. 2018; 20(3): 294-9.

37. Drápela S, Bouchal J, Jolly MK, Culig Z, Souček K. ZEB1: A critical regulator of cell plasticity, dna damage response, and therapy resistance. Front Mol Biosci. 2020; 7: 36. doi: 10.3389/ fmolb.2020.00036.

38. Loric S, Paradis V, Gala JL, Berteau P, Bedossa P, Benoit G, et al. Abnormal E-cadherin expression and prostate cell blood dissemination as markers of biological recurrence in cancer. Eur J Cancer. 2001; 37(12): 1475-81. 